\title{
Editorial
}

\section{OS SESSENTA ANOS DE ARQUIVOS DE NEURO-PSIQUIATRIA}

Com este número Dezembro 2002, completamse os sessenta primeiros anos de publicação deste periódico. No mês de junho de 1943, veio a lume o primeiro número de Arquivos de Neuro-Psiquiatria. As equipes dos dois serviços universitários de neurologia à época existentes em São Paulo - da Faculdade de Medicina da Universidade de São Paulo (FMUSP), chefiado pelo Prof. Dr. Adherbal Tolosa; da Escola Paulista de Medicina (EPM), chefiado pelo Prof. Dr. Paulino Watt Longo - emprestaram todo o apoio ao Dr. Oswaldo Lange, então Professor Assistente de Neurologia da FMUSP, para que levasse avante a árdua tarefa que se impusera, a de editar uma revista de referência na área de neuro-psiquiatria. Essa revista deveria alcançar merecido relevo entre suas congêneres nacionais e do exterior, em justa homenagem à memória do Prof. Dr. Enjolras Vampré, fundador da neurologia paulista, plasmador de homens como Tolosa, Longo e Lange. Foi a vontade e a determinação de um deles, Oswaldo Lange, que deu vida e garantiu a continuidade e a regularidade da publicação deste periódico enquanto viveu. Seu exemplo e suas lições norteiam os seus continuadores.

Ao encerrar o Volume 1, no número Dezembro, o Dr. Oswaldo Lange noticia em Nota Editorial (pgs. 344-345), que: “Este número, o terceiro publicado até agora, encerra o volume I de Arquivos de NeuroPsiquiatria. Por ter sido possível iniciar a publicação somente em Junho de 1943 e tratando-se de órgão trimestral, o volume I, enfeixando 4 números, terminaria em Março de 1944. Essa era a idéia primitiva. Ponderando, porém, as dificuldades que assim adviriam para a catalogação da revista, decidiu a direção, agora, que o volume I conteria somente matéria publicada em 1943, ajustando-se, desse modo, ano (1943) e volume (1)". O trabalho editorial émotivo de outras das sábias considerações do Dr. Oswaldo Lange nessa mesma Nota Editorial: "De nossa parte ainda há muito que fazer. Embora tenhamos aprendido bastante com os três números já publicados, e embora a revista esteja mais ou menos estandartizada no que diz respeito à parte tipográfi- ca, na disposição dos trabalhos e na apresentação, reconhecemos que ainda há falhas e grandes, atinentes umas à nossa pouca experiência, outras a dificuldades técnicas, e outras atribuíveis aos autores. Procuraremos remover, dentro das possibilidades materiais do momento, as falhas que nos tocarem.".

E assim foi. O Dr. Oswaldo Lange trabalhou metodicamente até o último de seus dias, em 1986, para aprimorar a revista. Editou ele até o último número (Dezembro) do Volume 44 (1986) e deixou muita coisa preparada para o Volume 45. Paulatinamente, conseguiu ele que a revista ampliasse seu alcance, publicando artigos preparados praticamente em todos os centros neurológicos brasileiros e, mesmo, em centros de outros países. A partir de 1970, o periódico passou a ser o jornal oficial da Academia Brasileira de Neurologia (ABN), automaticamente tornando-se vinculado à Federação Mundial de Neurologia. Por outro lado, a manutenção da regularidade e da periodicidade absolutas, de que tanto ele se orgulhava, e a qualidade do conteúdo dos artigos levaram a que, nos anos sessenta, o periódico fosse selecionado para o Index Medicus. Seguiram-se a indexação e catalogação em outras bases de dados, como ULACS, da Biblioteca Regional de Medicina da Organização Pan-Americana de Saúde (BIREME).

Os membros de sua equipe editorial, seus continuadores, para que não houvesse qualquer interrupção no trajeto da revista, fundaram a "Associação Arquivos de Neuro-Psiquiatria Dr. Oswaldo Lange" para dar continuidade à obra do Editor Fundador, buscando seguir seus ensinamentos e, com respeito, honrar os sadios princípios que marcaram a atuação dele à frente do periódico. Não tem sido um trabalho fácil, é árduo dar continuidade à obra de um batalhador gigante como foi Oswaldo Lange. A Associação conseguiu manter absolutas a regularidade e a periodicidade da revista, assim como o padrão de qualidade dos artigos aceitos para publicação. Para aprimorar a seleção dos artigos aceitos, nos anos noventa, passou a adotar o sistema de arbitragem por pares (peer referees) e as normas do ICMJE (International Committee of M edical J ournals 
Editors); associou-se à ABEC (Associação Brasileira de Editores Científicos); obteve o apoio do CNPq (Programa Editorial); viu os artigos pontuados no Neuroscience Citation Index do ISI (Institute for Scientific Information), os artigos incluídos on-line no MEDUNE (Index Medicus) e, a partir de 1998, no já consagrado sistema de revistas on-line, SciELO, que leva o selo da BIREME. Complementarmente, também nos anos noventa, introduziu no periódico as seções Correspondência e Theses: a primeira para a discussão de artigos publicados e a segunda, para o registro em inglês dos abstracts de dissertações e de teses de neurociências defendidas e aprovadas em instituições universitárias. O progressivo aumento da demanda de publicação de artigos, por sua vez, levou a que seis números passassem a aparecer anualmente, pela duplicação dos números Junho e Setembro, em A e B. Ainda, a partir de 2000, a adoção do atual formato da revista $(21 \times 28 \mathrm{~cm}$, em lugar de $16 \times 23 \mathrm{~cm}$ ). Todos esses passos têm garantido o reconhecimento da qualidade do que é selecionado para publicação no periódico, sua visibilidade e o alcance da comunicação científico-tecnológica que contém. Hoje, o periódico se encontra em todas as instituições brasileiras em que há núcleos de estudos de neurociências e em muitos aos redor do mundo, particularmente na América Latina. Igualmente, a revista é presença obrigatória no material de leitura dos que estudam o sistema nervoso, neurologistas ou não, sócios da ABN ou não.

Alguns dados acerca dos três últimos anos ilustram a dimensão do trabalho desenvolvido.

O número de artigos originais publicados em 1999 foi 169; em 2000, 179; em 2001, 186. Esses números expressam o resultado de todo um trabaIho editorial, que se inicia quando os autores submetem seus artigos: o editor encaminha cada artigo para pelo menos dois colegas que atuam na área a que diz respeito a pesquisa de que se originou $o$ manuscrito; as sugestões destes orientam o Corpo Editorial quanto a (a) aceitar diretamente o artigo, o que é raro, ou (b) recusar o artigo ou (c) reencaminhá-lo aos autores com as sugestões de seus parese dos editores para a introdução das modificações julgadas oportunas e necessárias, o que é o mais comum; neste último caso, os autores introduzem as modificações solicitadas e reencaminham o novo texto para revisão editorial; caso discordem, os autores enviam sua opinião que passa novamente pelo crivo editorial e pelo colega avaliador, ou não reencaminham o artigo para reavaliação, automaticamente retirando o manuscrito do processo seletivo da série de artigos a publicar. Aceito o artigo em sua forma final, isto é comunicado ao autor, juntamente com a previsão do número do periódico em que o artigo virá a lume.

Outros dados acerca do desempenho científico e técnico do periódico se encontram nos relatórios referentes a 1999, 2000 e 2001 (Vols. 57, 58 e 59), que foram encaminhados ao CNPq e que complementam este editorial (ver pgs. seguintes).

A equipe da Associação muito deve aos colegas que, desinteressadamente, têm incluído entre suas tarefas universitárias, a delicada missão de tecnicamente avaliar os artigos, participando do sistema de revisão por pares. Em 2001, foram eles 381, cujos nomes constam do Agradecimento aos Avaliadores publicado no número Dezembro 2001 (Arq Neuropsiquiatr 2001; 59:987-991). Com eles e com os autores dos artigos e seus leitores, a equipe reparte a alegria de comemorar os sessenta anos de Arquivos de Neuro-Psiquiatria, assim como com o pessoal de suporte técnico, aqui particularmente lembrados aqueles da Gráfica Ribeiro, e de publicidade, na pessoa de Pedro de Barros Silva, da EPM - Editora de Projetos Médicos.

Os colegas assinantes do periódico são aqui lembrados de modo todo especial pois, somados um-aum, garantiram que continuasse um órgão de comunicação independente, de linha firme e forte. Assim, também, aqueles colegas que, com o mesmo espírito, prestigiaram a revista com inserções, anunciando suas atividades profissionais.

Mas, sobretudo, é com muito carinho que a equipe da Associação que cuida e edita a revista dedica a alegria que cerca o sexagésimo aniversário de Arquivos de Neuro-Psiquiatria ao seu êmulo, o Editor Fundador Dr. Oswaldo Lange.

Com Marília Lange Spina França, Adriana Spina França Machado, Luís dos Ramos Machado, José Antonio Livramento, Luciano Spina França e, a mais nova colaboradora, Sylvia Regina Mielli, integrantes da equipe de Arquivos de Neuro-Psiquiatria,

\author{
ANTONIO SPINA-FRANÇA
} Editor Executivo 